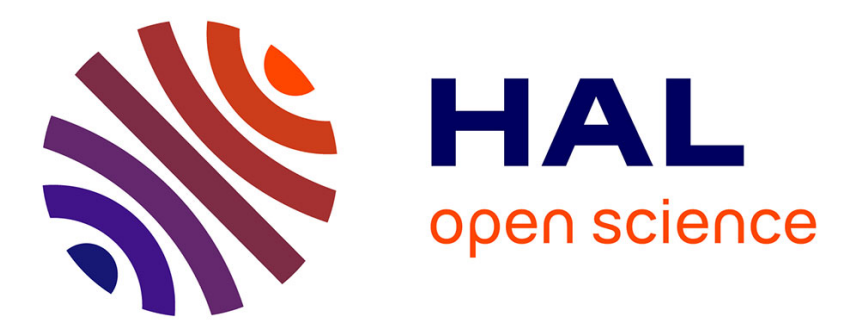

\title{
How good is quality-of-life for children receiving home parenteral nutrition? - A pilot study
}

Léa Chantal Tran, Gill Lazonby, Remy Morello, Dominique Pham, Donna Ellis, Jenny Goldthorpe, Natalia Iglesias, Julie Steele, Veena Zamvar, John William Lambert Puntis, et al.

\section{To cite this version:}

Léa Chantal Tran, Gill Lazonby, Remy Morello, Dominique Pham, Donna Ellis, et al.. How good is quality-of-life for children receiving home parenteral nutrition? - A pilot study. Clinical Nutrition ESPEN, 2019, 29, pp.119 - 124. 10.1016/j.clnesp.2018.11.009 . hal-03486594

\section{HAL Id: hal-03486594 \\ https://hal.science/hal-03486594}

Submitted on 20 Dec 2021

HAL is a multi-disciplinary open access archive for the deposit and dissemination of scientific research documents, whether they are published or not. The documents may come from teaching and research institutions in France or abroad, or from public or private research centers.
L'archive ouverte pluridisciplinaire HAL, est destinée au dépôt et à la diffusion de documents scientifiques de niveau recherche, publiés ou non, émanant des établissements d'enseignement et de recherche français ou étrangers, des laboratoires publics ou privés.

\section{(ㅇ)(1) $\$$}

Distributed under a Creative Commons Attribution - NonCommerciall 4.0 International 
1 How good is quality-of-life for children receiving Home Parenteral Nutrition? -

a pilot study.

3

4 Léa Chantal Tran ${ }^{1,3}$, Doctor of Medicine; lea.tran33@gmail.com

$5 \quad$ Gill Lazonby ${ }^{1}$, Nutrition Nurse Specialist; gilllazonby@nhs.net

6 Remy Morello², Doctor of Medicine; morello-r@chu-caen.fr

7 Dominique Pham², Doctor of Medicine; pham-ad@chu-caen.fr

8 Donna Ellis ${ }^{1}$, Nutrition Nurse Specialist; donna.ellis2@nhs.net

9 Jenny Goldthorpe ${ }^{1}$, Nutrition Nurse Specialist; jenny.goldthorpe@nhs.net

10 Natalia Iglesias ${ }^{1}$, Parenteral Nutrition Pharmacist; natalia.iglesias@nhs.net

11 Julie Steele ${ }^{1}$, Specialist Dietitian for intestinal failure and rehabilitation; juliesteele@nhs.net

12 Veena Zamvar ${ }^{1}$, Doctor of Medicine; veena.zamvar@nhs.net

13 John William Lambert Puntis ${ }^{1}$, Doctor of Medicine; john.puntis@nhs.net

14 Rakesh Vora', Doctor of Medicine; rakeshvora@nhs.net

${ }^{1}$ Department of Paediatric Gastroenterology and Nutrition, The General Infirmary at Leeds,

Great George Street, Leeds LS1 3EX, West Yorkshire, UK

${ }^{2}$ Department of Statistics and Clinical research, CHU de Caen, Caen, Normandy, France

${ }^{3}$ Department of Pediatrics, CHU d'Amiens, Amiens, Picardie, France

Corresponding author:

Dr Léa C. Tran, lea.tran33@gmail.com 


\section{Abstract}

2 Background \& Aims: Children on home parenteral nutrition and their parents not

3 only engage with complex nutritional issues but also have to manage difficult social

4 and financial problems with social and clinical support that may not always meet their

5 needs. Baxter's HPN-QOL questionnaire, assesses the QOL of adult patients treated

6 with HPN, and has been developed rigorously using standard guidelines, measuring

7 various dimensions of QOL. Our aim was to use this tool to explore how HPN

8 influences the QOL of paediatric patients.

9 Methods: The HPN-QOL questionnaire was modified to suit a paediatric HPN population. Data on demographics, aetiology of intestinal failure and duration of HPN were collected from a departmental database. Quality-of-Life grading of functional and symptom scales, HPN specific items and overall QOL Numerical Rating Scales were determined.

Results: Fourteen out of 17 families returned the completed questionnaires. QOL was significantly impaired by increased dependency regarding items of daily living such as eating, dressing, washing, and mobility, but was not affected in the domains

17 of school attendance, general fatigue, pain and body image. There were no significant differences in QOL when patients with and without enterostomy were compared. Patients felt well supported by the hospital nutrition team in managing logistics related to HPN.

Conclusions: QOL in HPN patients was not significantly affected by the medical aspects of care. This descriptive study highlights the need for further integration of 
1 medical and social care in order to support families of children receiving HPN as

2 QOL was impaired in relation to activities of daily living and social functioning. 
1 Keywords:

2 Home parenteral nutrition; Quality-of-Life; Intestinal Failure; Short Bowel Syndrome;

$3 \quad$ Nutrition team

4

5

6 Highlights

7

- Baxter's HPN-QOL tool has been adapted for paediatric patients and used to

8 assess QOL

- Overall, children on home parenteral nutrition have a good quality-of-life

- Improved social care may be of particular value for these families 


\section{Abbreviations}

2

3 CVC: Central venous catheter

4 HPN: Home parenteral nutrition

5 IF: Intestinal failure

6 PN: Parenteral nutrition

7 QOL: Quality-of-life

8 


\section{Introduction}

Home Parenteral Nutrition (HPN) allows patients with intestinal failure (IF) to be managed in the community during and after intestinal adaptation to bridge the period of adaptation $(1,2)$. Intestinal failure may be temporary in some children with short bowel syndrome so that weaning from PN can occur over time (3). Providing PN to children is a multidisciplinary team effort requiring the expertise of a skilled nutrition team (3-5). Each team member plays a specific role, providing an overall safe package of care centred around the child, with crucial involvement from other professionals, such as interventional radiologist and surgeons. When the child is to be discharged home on PN, support from community services is essential, as well as that from expert parents, who are taught the complex skills required prior to leaving hospital.

Issues commonly associated with HPN, including risk of sepsis and protecting the central venous catheter (CVC), represent a major burden of care and responsibility for parents (6). The presence of stoma or an enteral feeding tube adds further complexity and in older children may negatively affect their body image. The potential for complications such as CVC-related sepsis, liver failure, and repeated hospitalisations are undoubtedly a source of anxiety. Leaking stoma bags or watery diarrhoea, excessive flatulence and abdominal pain are embarrassing, distressing and difficult to manage. These issues can have a major impact on patients' qualityof-life (QOL), school attendance, their sense of independence, sleep pattern and parents' ability to work (7). Some HPN patients may over time experience improvement in symptoms related to their underlying condition, but they still require 
1 ongoing nutritional support. PN maintains nutritional status and both prolongs and

2 enhances life, resulting in a better overall survival (8).

3 Defining patients' QOL is a difficult task when considering the subjectivity

4 around quantifying a sense of well-being, but parameters such as emotions, social

5 environment, occupations and physical feeling are clearly relevant. We considered

6 that using a standardized, validated and specific HPN questionnaire that had been

7 widely used was the most appropriate method (9). Baxter et al (10) designed a HPN-

8 QOL questionnaire sent to 100 adults receiving HPN. The aim was to assess the

9 impact of treatment on patients' feelings, their functional capacity and symptoms with

10 which they had to cope. This approach allowed a robust and objective evaluation of

11 the QOL on HPN. As no such instrument has been developed for children, our

12 objectives were to modify the Baxter questionnaire for use with paediatric patients

13 receiving HPN and to use it to explore what was important to child and family in

14 order to improve future care. 


\section{Materials and Methods}

\section{Participants}

We conducted a descriptive, cross-sectional study, over a 3-month period (from May $15^{\text {th }}$ to July $30^{\text {th }}, 2016$ ), in patients care for by Leeds Teaching Hospitals NHS Trust. All children who received HPN during the study period were invited to participate. Demographics from the cohort were described (age, duration of HPN, aetiology of IF, presence of stoma, family structure and employment).

The study was fully discussed with the family in the outpatient clinic where they were given a copy of the questionnaire; consent to participate was implied by return of a completed questionnaire. The questionnaire was anonymous but there was a possibility that families could be identified by nutrition team members through some of the demographic details provided. For this reason, after extracting and pooling data, the questionnaires were destroyed. The primary intention of the study was to explore through assessment of QOL how effective our service was in supporting families. A formal opinion from a Research Ethics Committee was not requested.

\section{Questionnaire}

The original 48 item Baxter scale was reduced to 46 items, comprised of the same functional considerations (general health, physical and emotional function), HPN related items (nutrition team and use of ambulatory pump), items about symptoms, and three related to QOL rating. Each item was associated with qualitative answers, composed of four or five scores, which were ordered from worst (score 1 ) to the best possible answer (score 4 or 5 ); except for the three QOL 
1 numerical rating scales (Fig 1). Increasing positive scores represented better QOL

2 and negative scores poor quality. Our adaptations were made in order to better fit

3 with children's way of life: items related to attractiveness $(n=1)$, adults' activities

4 such as work $(n=2)$, shopping $(n=2)$, or sexual life $(n=3)$ were removed, while

5 items related to school $(n=3)$ and to nocturnal stooling $(n-1)$ were added. The

6 answers to some questions were combined. For example, "do you feel depressed?"

7 and "do you feel tense" both relate to depression. The higher the scores, the better

8 the QOL.

9

The questionnaires were either given to parents attending HPN clinics or posted with a stamped addressed envelope to families at their home. All questionnaires were filled anonymously, either by the parents and/or by the patient if they were old enough to understand.

\section{Statistics}

Data was collated on Microsoft Excel sheet and analysed using the median values of the reported answers. Chi-square and Fisher tests have been used to compare patients with and without stoma. A $p$-value $<0.05$ was considered significant. 


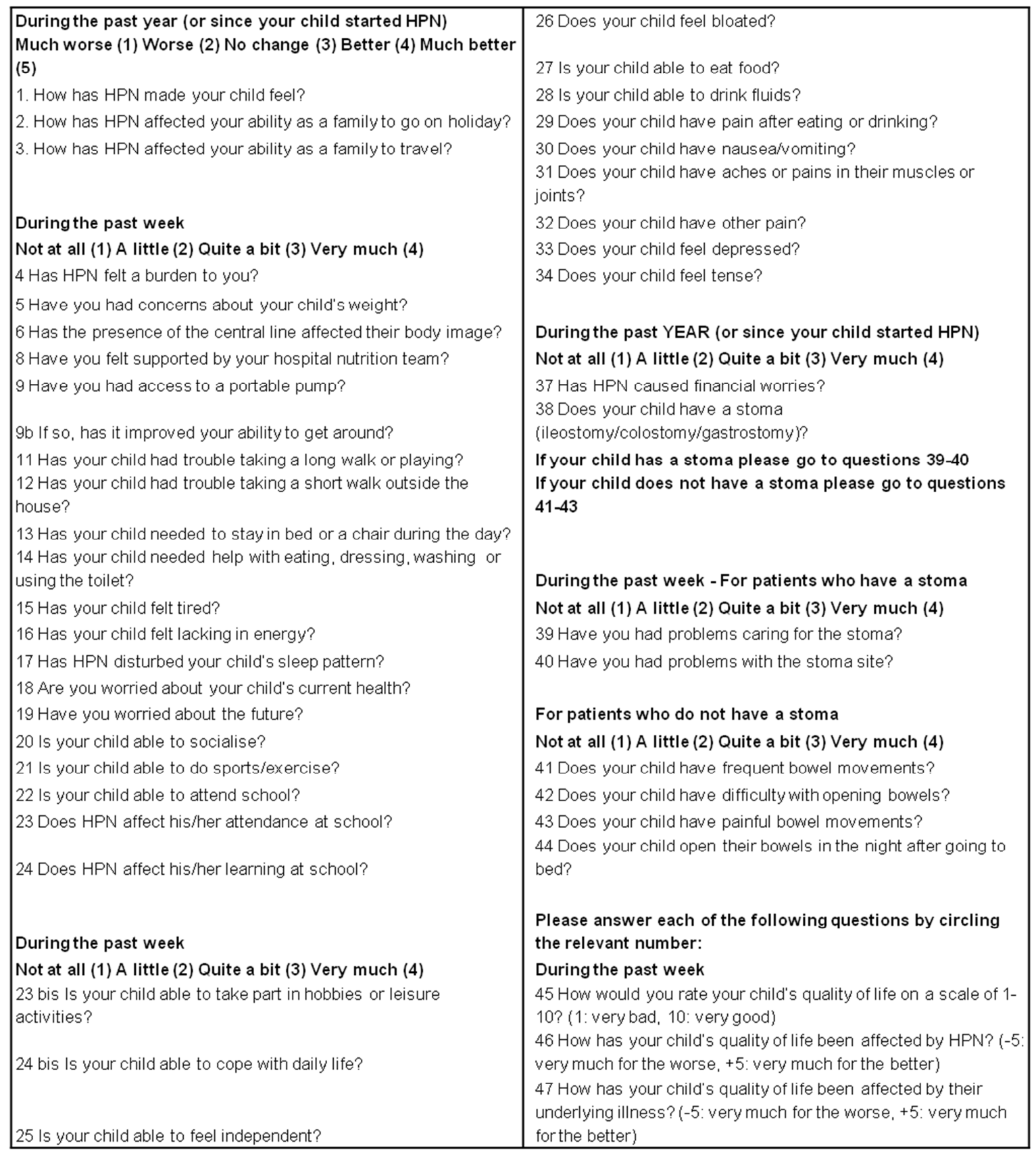

2 Figure 1. The HPN-QOL from Baxter et al. (10) modified for paediatric patients. non-applicable) which had to be circled by the patient or parent(s). 


\section{Results:}

\section{Demographics}

3 Fourteen out of 17 families returned the completed questionnaire. Thirteen percent

4 of questions did not have a valid answer (i.e. no selected answer for a particular

5 item). During the study period, the Leeds HPN cohort was two third males, aged

6 between 1 and 17 years-old, and the ratio of patients with and without an

7 enterostomy was 4/3. The median (range) duration of HPN was 32 months (8-182

$8 \mathrm{~m})$. The main cause of IF was short bowel syndrome $(n=10$; mostly complex

9 gastroschisis), followed by motility disorders $(n=6)$, such as long segment

10 Hirschsprung's disease, and one case of microvillous inclusion disease.

11 There was one single parent family; three couples were separated and two others

12 had adopted children (Table 1). In four families parents were unemployed.

\begin{tabular}{|c|c|}
\hline & Cohort $(n=17)$ \\
\hline Number of participants $(\%)$ & $14(82 \%)$ \\
\hline Male (\%) & $11(79 \%)$ \\
\hline Median age in years [range] & $4[1-17]$ \\
\hline Patients with a stoma (\%) & $10(59 \%)$ \\
\hline Median duration on HPN in months [range] & 32 [8-182] \\
\hline \multicolumn{2}{|l|}{ Aetiology: } \\
\hline Short Bowel Syndrome & 10 \\
\hline Dysmotility & 6 \\
\hline Microvillous Inclusion Disease & 1 \\
\hline Median distance in km from hospital [range] & $19[5-129]$ \\
\hline Number of single parents families (\%) & $4(24 \%)$ \\
\hline Number of families having a job (\%) & $10(71 \%)$ \\
\hline
\end{tabular}




\section{Items of daily living (Fig 2A and 2B)}

2 Overall, parents reported their children were able to cope with daily living activities

3 and to have a social life. An important need to rest was expressed in about one-fifth

4 of these patients, while taking a short walk was very difficult for only $7 \%$. However,

5 half of these families declared problems associated with simple tasks, such as

6 eating, dressing, washing, or resting. For the majority, learning at school, having

7 hobbies and doing sports were considered to be difficult.

9 Parental anxiety (Fig 2C)

10 Parents did not describe any financial worries and felt supported by the nutrition

11 team. However, items associated with travel, leisure and worries about the future

12 were highlighted, as well as issues related to stoma care.

\section{Numerical scales of QOL (Fig 3)}

15 The median overall QOL score was 8 out of 10 (10 was the best answer and 0 the

16 worst), for 13 answers.

17 When considering how QOL was affected by HPN, the median score was 3, on a scale between -5 (worst collected answer: -1 ) and +5 (best collected answer: +5 ), for 13 answers. For QOL affected by the underlying disease, the median score was 0 , on a scale between -5 (worst value) and +5 (best value), for 13 answers. 


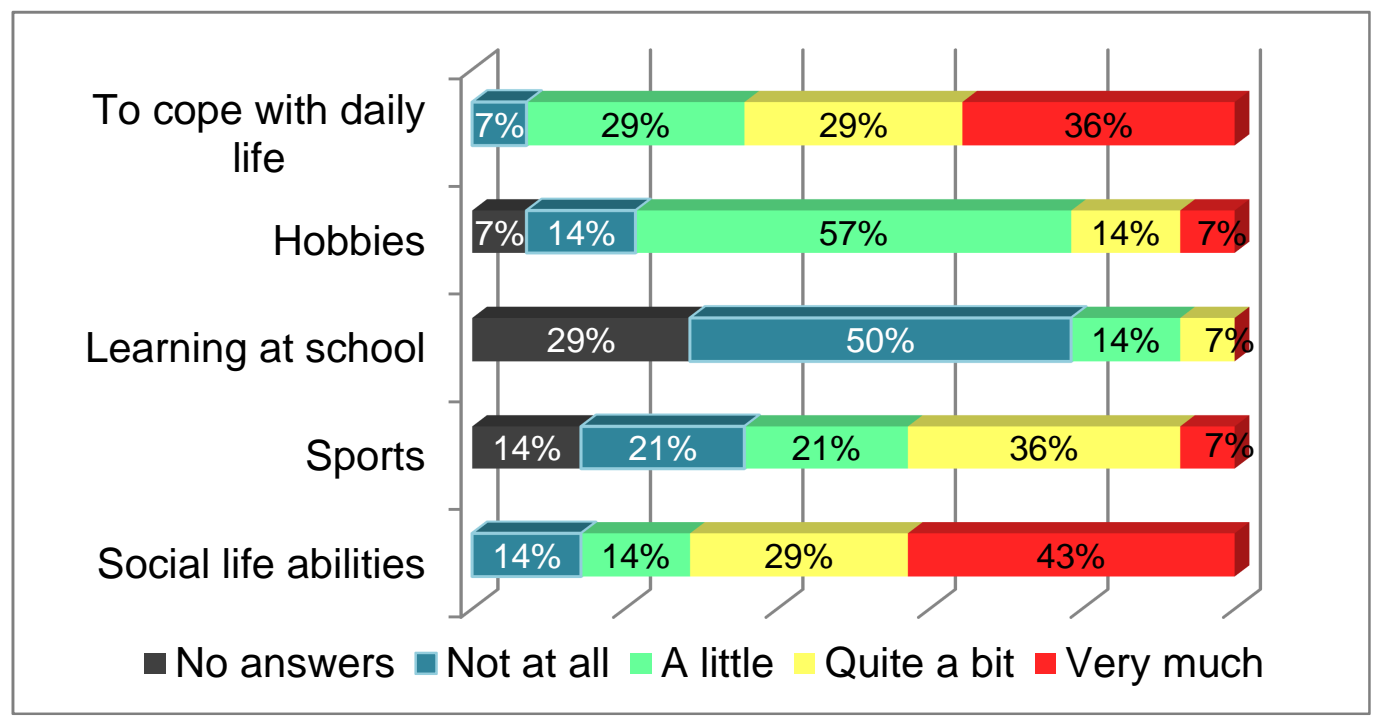

\section{Figure $2 \mathrm{~A}$ : Answers about physical and social abilities}

On the left side, items regarding children's abilities to do daily life activities. The horizontal bars represent the percentages of different answers to these items. Five different colors correspond to each type of answers : arev means

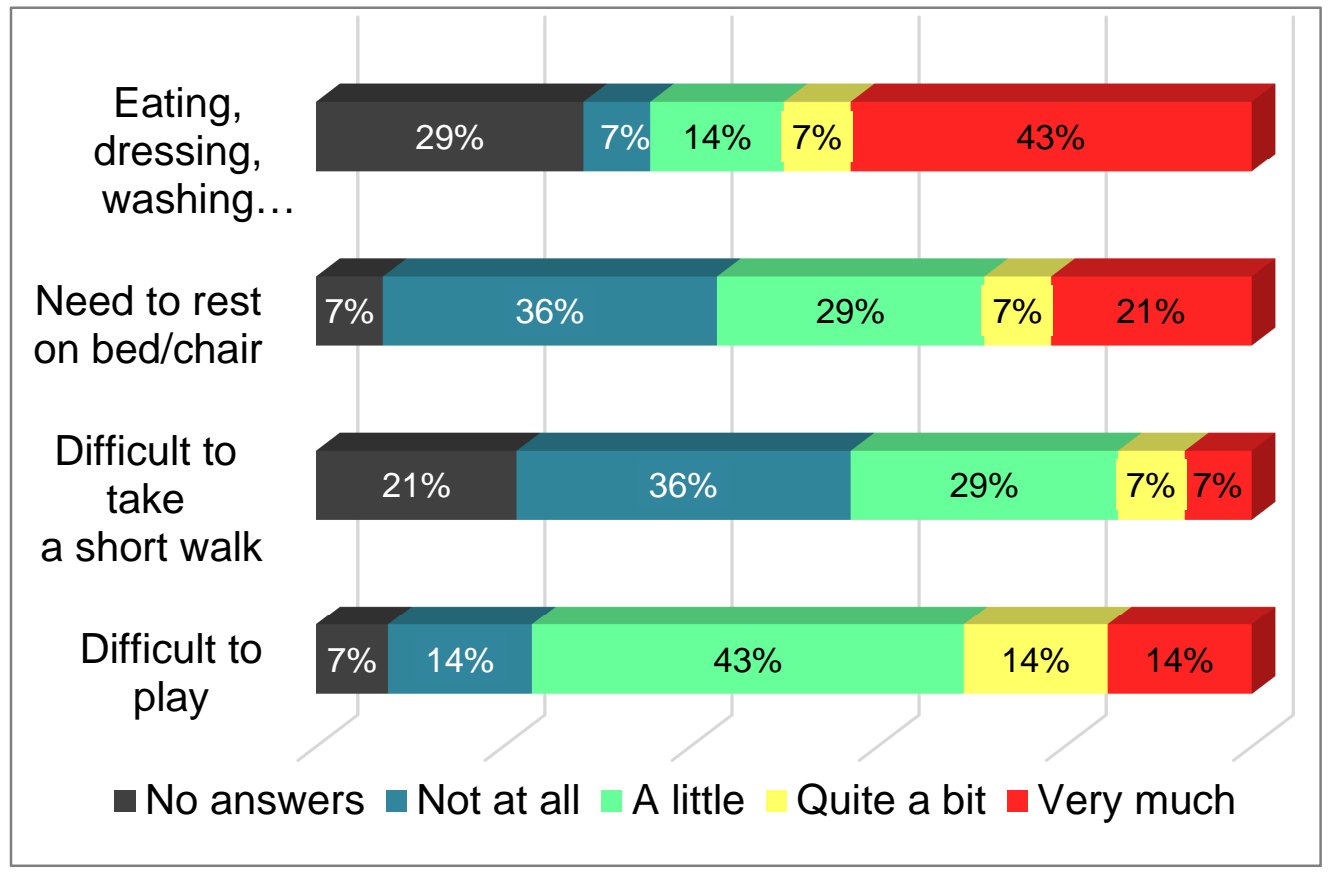

Figure 2B : Answers about dependency

On the left side, items regarding children's dependency with doing simple tasks of daily life.

The horizontal bars represent the percentages of different answers to these 


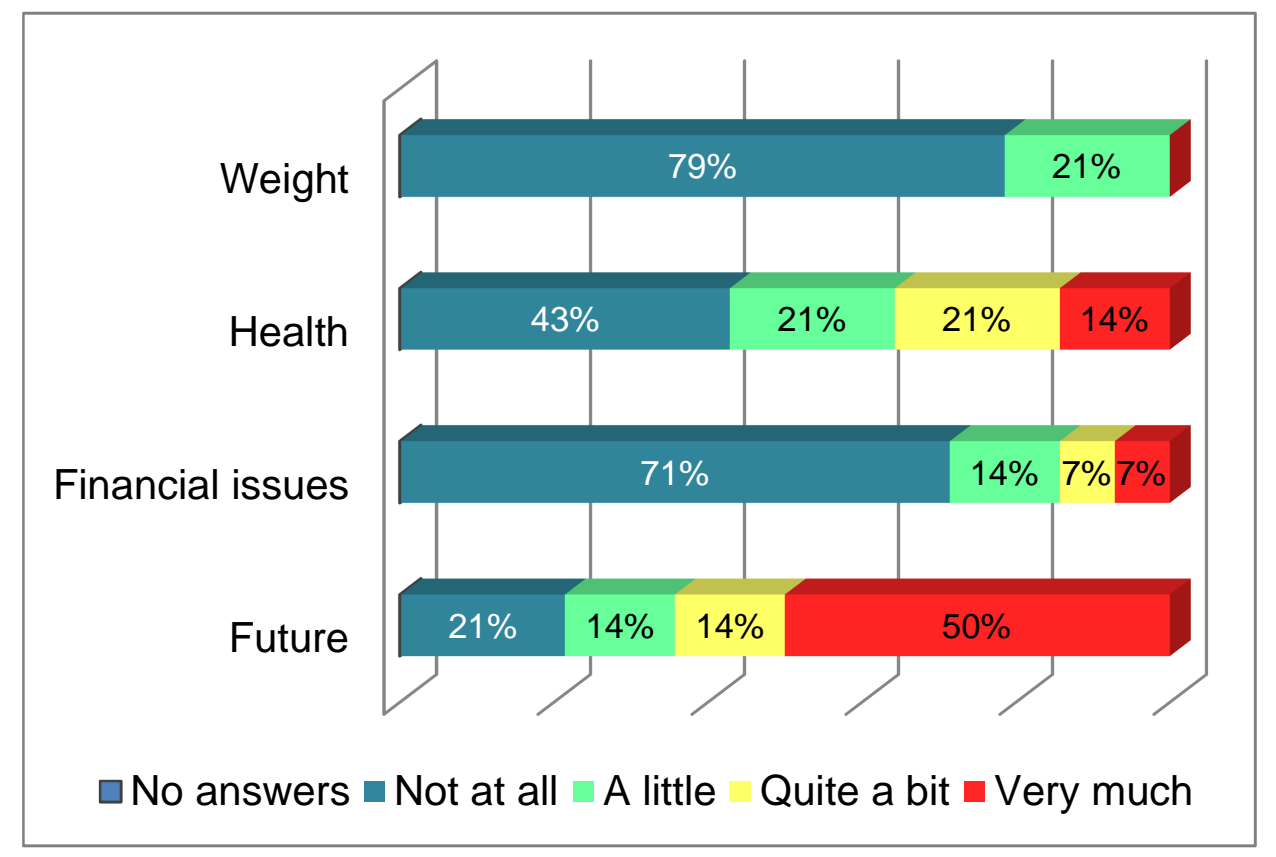

\section{Figure 2C : Answers about parental concerns}

On the left side, items regarding parents' concerns about their child's weight, health, their financial difficulties and worries about their child's future.

The horizontal bars represent the percentages of different answers to these items. Five different colors correspond to each tvpe of answers : arev means

\section{Differences between children with or without stoma}

4 For families completing the questionnaire, no statistical difference was observed

5 between the stoma group $(n=8)$ and the group without stoma $(n=6)$ (Table 2). Four

6 patients were younger than 3 years at the time of the study. School attendances

7 were similar among both groups. Patients without stoma felt better overall and also

8 more able to do sports or exercise, to engage in leisure activities, to socialize and to

9 go to school. Gastrointestinal symptoms, such as bloating, nausea, vomiting or pain

10 after eating were slightly more frequent among patients without stoma. Interestingly,

11 there were no statistical differences in QOL items, considering both the overall

12 rating, the QOL affected by HPN rating and the QOL affected by the underlying

13 disease rating. 

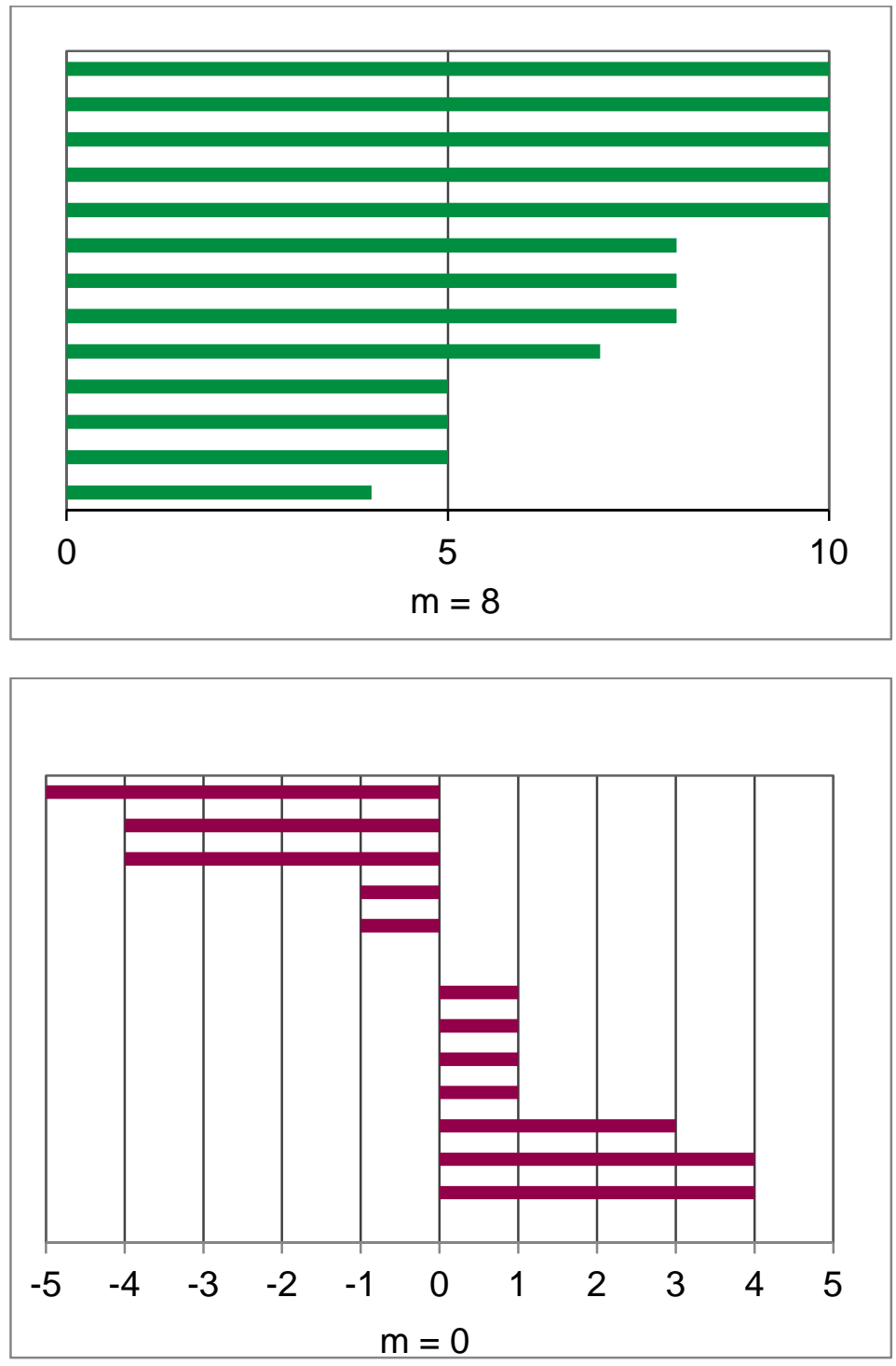

2

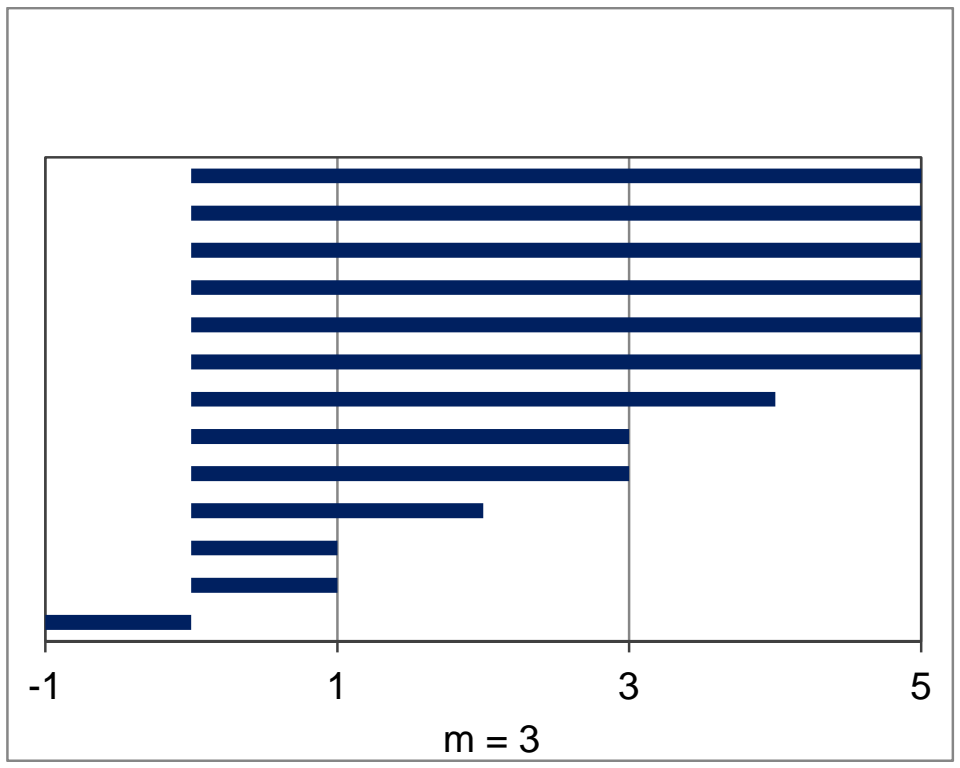

Figure 3. Numerical scales to evaluate the Quality of Life (QOL) of children receiving Home Parenteral Nutrition (HPN): answers from 14 families.

On the upper figure, global score of QOL, between 0 (worse) and 10 (best); on the middle, influence of HPN on QOL, between -5 (much worse) and +5 (much better); on the lower figure, influence of the underlying disease on QOL, between -5 (much worse) and +5 (much better).

$\mathrm{m}=$ mean value; each bar corresponds to one answer 


\begin{tabular}{|lccc|}
\hline \multicolumn{1}{|c}{ Theme } & $\begin{array}{c}\text { Number } \\
\text { of items }\end{array}$ & $\begin{array}{c}\text { Stoma } \\
(\mathrm{n}=8)\end{array}$ & $\begin{array}{c}\text { No stoma } \\
(\mathrm{n}=6)\end{array}$ \\
\hline $\begin{array}{l}\text { 1. Global feeling: } \\
\text { "Much better" }\end{array}$ & 1 & $3(38 \%)$ & $5(83 \%)$ \\
\hline $\begin{array}{l}\text { 2. To feel depressed: } \\
\text { "Not at all" }\end{array}$ & 2 & $1(67 \%)$ & $3(63 \%)$ \\
\hline $\begin{array}{l}\text { 3. Effects on school } \\
\text { attendance: "Not at all" }\end{array}$ & 2 & $5(64 \%)$ & $3(67 \%)$ \\
\hline $\begin{array}{l}\text { 4. Physical functions: } \\
\text { "Very much" } \triangle\end{array}$ & 4 & $1(17 \%)$ & $2(41 \%)$ \\
\hline $\begin{array}{l}\text { 5. To cope with daily } \\
\text { life, to feel } \\
\text { independent: "Quite a } \\
\text { bit" }\end{array}$ & 2 & $1(7 \%)$ & $3(59 \%)$ \\
\hline $\begin{array}{l}\text { 6. Fatigue: "Not at all" } \\
\begin{array}{l}\text { 7. Gastrointestinal } \\
\text { symptoms }\end{array}\end{array}$ & 2 & $5(63 \%)$ & $3(42 \%)$ \\
\hline $\begin{array}{l}\text { 8. Parental anxiety } \\
\text { "Not at all" }\end{array}$ & 5 & $2(32 \%)$ & $2(45 \%)$ \\
\hline
\end{tabular}

(1)

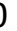

Table 2. Adjusted percentages of groups of patients with $(n=8)$ and without stoma $(n=6)$ according to the questions theme.

\footnotetext{
$\Delta:$ ability to do sports or exercise, to engage in leisure activities, to socialise and to go to school

s: bloating, nausea, vomiting or pain after eating
$\diamond$ : burden of undertaking HPN, financial worries and concerns about the child's weight, health and future




\section{Discussion}

2 We have shown in our cohort that QOL of children receiving HPN is globally good

3 (overall score of $8 / 10$ ). This finding is consistent with the study by Gottrand et al. (7),

4 showing that QOL was similar between HPN-dependent and healthy children,

5 suggesting the effectiveness of coping strategies. In this study, although infants and

6 younger children were more autonomous and needed less attention, adolescents

7 showed lower QOL with regard to social life and concerns for the future. In contrast,

8 in our cohort, there were no significant differences between children with and without

9 stoma.

10 In studies by Engstrom and Emedo $(11,12)$, children receiving HPN were found to be

11 psychologically distressed when assessed by standard questionnaire, and to be aware that their lives were restricted in some respects. . To address negative effects on QOL, Engstrom et al. suggested better contacts with the family through a multidisciplinary team approach and encouraged families to meet together to share their feelings and generate effective mutual support. Similarly, Emedo and coworkers highlighted the importance of support from peers and good counselling as near to home as possible, and extolled the benefits of owning pets. They concluded that the impact of HPN on QOL was far less than the effects of the underlying chronic disease.

In a systematic review of the literature of 26 studies including HPN patients aged from 17 to 87 years, treated by HPN from 1 month to 28 years, Huisman de Waal et al. (13) concluded that patients experienced a moderate to good QOL, even though they suffered from depression, fatigue and limited social life. They recommended 
1 early interventions in developing coping with these difficulties, starting from when the

2 patient begins to be trained to manage HPN.

To determine whether the consequences on QOL are direct results of HPN itself or are associated with the underlying disease is challenging. HPN does allow children to have a relatively normal life outside hospital and for them to mix socially with other children of their age. However, the CVC and the stoma are not only constant reminders of HPN dependence (together with necessary restrictions, for example when swimming or during contact sports), but they are also a constant source of worry in relation to infection, accidental damage or dislodgement. These are the reasons why parents have to be educated very carefully in order to minimize risk of complications. HPN involves high work load and responsibilities and parents know very well how their child's well-being and health might be influenced by their capacity to take care of them. In their study, Friedman-Gruszczyńska et al (14) compared the incidence of catheter infections in trained parents to the hospital pharmacy, and showed that trained parents were safer. That being said, the impact of HPN management on the lives of families caring for their child at home is significant, such that improved social support is likely to important. In our study, although achieving simple tasks of daily life did not seem to be considered burdensome, parents and their children were likely to encounter difficulties doing them. Almost one-quarter of our families were single-parent ones, for whom social assistance and community nursing support may be essential. This element of care has not always been highlighted in HPN guidelines (15) but needs to be taken into account in clinical practice. 
After social life, HPN had the next highest impact on freedom of movement,

2 with restricted travel being a common source of frustration. The main limiting factors are stability issues of PN bags, as well as expensive travel insurance. Some airline companies provide medical assistance on request. Charities and hospices are

5 further sources of support for parents, including organisations such as Patients on

6 Intravenous \& Nasogastric Nutrition Therapy, Dreams Come True or Destination

7 Florida (16-18) in the UK. Trips abroad require considerable organisation and

8 advanced planning, but can be hugely beneficial experiences for children (19).

9 Parents worries about their child's future were a recurring issue. Among the eight 10 adults with SBS receiving HPN assessed by Carlsson et al. (20), only half of them

11 had a full-time job, perhaps because their situation made them less attractive for 12 employers.

Our study suggests that a good QOL can be achieved for HPN patients by developing strong links between the support of a trained hospital nutrition team and the community nursing team. The nutrition team provides ongoing support to families through telephone calls, emails and texts. Training sessions and competency assessment for parents and community nurses include CVC management, aseptic technique, blood sugar testing, starting and stopping intravenous fluids and parenteral nutrition, assessing gastrointestinal fluid losses, management of fever, recognizing an unwell child, as well as safety training for staff in nurseries and schools. Specialist nurses perform periodic home visits (particularly if there are concerns about management), or arrange urgent outpatient or day-case review when necessary. This approach to care is aimed at minimising catheter-related sepsis, the need for readmission to hospital, and the number of routine outpatient visits (once 
1 every three months). A weekly multidisciplinary team meeting allows assessment of

2 patients without seeing them, and is informed by feedback on clinical status according to a defined proforma from the community nurse. Furthermore, children can also develop coping strategies when supported by their parents, siblings and

5 their friends. Maintaining good peer relationships during usual childhood activities, as

6 well as taking care of household pets, are undoubtedly sources of happiness in

7 childhood (7), while children's compliance with treatment can be improved with their better understanding of their underlying condition.

Our study has several limitations. It was conducted among a small cohort, from one British city. We could have used questionnaires adapted to different age ranges or disease-specific questionnaires. Three families did not complete the questionnaires. We were not able to describe the profile or these non-responders, or determine who filled in the questionnaire (although most of our patients were too young to do this) because of the anonymous design of the study. Comparisons with a control group of patients having the same diseases but without IF and HPN and stratifying the results according to age could bring more precise results; a larger study in the future should incorporate this. The main strength of this study was the use of a detailed questionnaire that has been validated in adults receiving HPN and required only slight modification. The questionnaires were well accepted with a response rate of $82 \%$. Finally, QOL of children treated by HPN is not well described in the literature. It would be useful to repeat this study in a number of other centres working with a collaborative group such as the British Society of Paediatric Gastroenterology. Using the questionnaire in non-English speaking countries would not be justified by this pilot. 
1 In the future, follow-up questionnaires to our patients may be helpful in

2 demonstrating improvements after interventions have been put in place, and routine

3 use in HPN clinics will help us to involve young children and families in identifying

4 areas where further support is needed. Reassuringly, our results show that children

5 on HPN can have a good QOL. Key factors in this include ongoing support from the

6 hospital nutrition team following discharge from hospital and close liaison with

7 community services. The burden of care represented by HPN is probably under

8 recognised by social care agencies, and this consideration is most important for

9 those families who already struggle with issues such as being a lone parent or

10 unemployment (21). Greater integration between health and social care services in

11 the future may further assist families who take on such great home care

12 responsibilities. 


\section{Acknowledgements}

2 We thank our patients and their families for their contribution.

4 Statement of Authorship

5 The paper was drafted by Dr Tran and commented on by co-authors. After

6 amendments, the final draft was approved by all authors.

\section{Conflict of Interest Statement and Funding sources}

8 The authors have no conflicts of interest to report and have not received any funding

9 for this study.

10

11 
1. Pedrón-Giner C, Martínez-Costa C, Gómez-López L, Navas-López VM, Redecillas Ferreiro S, Moreno-Villares JM, et al. Home parenteral nutrition in children: procedures, experiences and reflections. Nutr Hosp. 2010 Oct;25(5):705-11.

2. Bielawska B, Allard JP. Parenteral Nutrition and Intestinal Failure. Nutrients [Internet]. 2017 May 6;9(5). Available from: https://www.ncbi.nlm.nih.gov/pmc/articles/PMC5452196/

3. Johnson T, Sexton E. Managing children and adolescents on parenteral nutrition: Challenges for the nutritional support team. Proc Nutr Soc. 2006 Aug;65(3):217-21.

4. Puntis JW, Holden CE, Smallman S, Finkel Y, George RH, Booth IW. Staff training: a key factor in reducing intravascular catheter sepsis. Arch Dis Child. 1991 Mar;66(3):335-7.

5. Colomb V, Ricour C. Home parenteral nutrition in children. Clin Nutr Edinb Scotl. 2003;22 Suppl 2:S57-59.

6. Puntis JW. Home parenteral nutrition. Arch Dis Child. 1995 Feb;72(2):186-90.

7. Gottrand F, Staszewski P, Colomb V, Loras-Duclaux I, Guimber D, Marinier E, et al. Satisfaction in different life domains in children receiving home parenteral nutrition and their families. J Pediatr. 2005 Jun;146(6):793-7.

8. Baxter JP, Fayers PM, McKinlay AW. A review of the quality of life of adult patients treated with long-term parenteral nutrition. Clin Nutr Edinb Scotl. 2006 Aug;25(4):543-53.

9. Howard L. Home parenteral nutrition: survival, cost, and quality of life. Gastroenterology. 2006 Feb;130(2 Suppl 1):S52-59.

10. Baxter JP, Fayers PM, McKinlay AW. The clinical and psychometric validation of a questionnaire to assess the quality of life of adult patients treated with longterm parenteral nutrition. JPEN J Parenter Enteral Nutr. 2010 Apr;34(2):131-42.

11. Engström I, Björnestam B, Finkel Y. Psychological distress associated with home parenteral nutrition in Swedish children, adolescents, and their parents: preliminary results. J Pediatr Gastroenterol Nutr. 2003 Sep;37(3):246-50.

12. Emedo M-J, Godfrey EI, Hill SM. A qualitative study of the quality of life of children receiving intravenous nutrition at home. J Pediatr Gastroenterol Nutr. 2010 Apr;50(4):431-40.

13. Huisman-de Waal G, Schoonhoven L, Jansen J, Wanten G, van Achterberg T. The impact of home parenteral nutrition on daily life-a review. Clin Nutr Edinb Scotl. 2007 Jun;26(3):275-88. 
14. Friedman-Gruszczyńska J, Ossolińska M, Popińska K, Książyk JB. Parenteral nutrition mixtures prepared at home by trained parents are as safe as pharmacy-made mixtures: a 3-y prospective study. Nutr Burbank Los Angel Cty Calif. 2013 Aug;29(7-8):988-92.

15. Koletzko B, Goulet O, Hunt J, Krohn K, Shamir R, Parenteral Nutrition Guidelines Working Group, et al. 1. Guidelines on Paediatric Parenteral Nutrition of the European Society of Paediatric Gastroenterology, Hepatology and Nutrition (ESPGHAN) and the European Society for Clinical Nutrition and Metabolism (ESPEN), Supported by the European Society of Paediatric Research (ESPR). J Pediatr Gastroenterol Nutr. 2005 Nov;41 Suppl 2:S1-87.

16. Patients On Intravenous \& Nasogastric Nutrition Therapy | PINNT [Internet]. [cited 2018 Feb 4]. Available from: http://pinnt.com/Home.aspx

17. True DC. Children's Charity in the UK [Internet]. Dreams Come True. [cited 2018 Feb 4]. Available from:

https://www.dreamscometrue.uk.com/1/1/childrens-charity-in-the-uk

18. Destination Florida home page [Internet]. Destination Florida home page. [cited 2018 Feb 4]. Available from: https://www.destinationflorida.org.uk

19. Mantegazza C, La Vela V, Hill S, Köglmeier J. Travelling With Children on Home Parenteral Nutrition. J Pediatr Gastroenterol Nutr. 2016 Jan;62(1):145-9.

20. Carlsson E, Bosaeus I, Nordgren S. Quality of life and concerns in patients with short bowel syndrome. Clin Nutr Edinb Scotl. 2003 Oct;22(5):445-52.

21. Zamvar V, Puntis JWL, Gupte G et al. Social circumstances and medical complications in children with intestinal failure. Arch Dis Child 2014;99:336-41 